\title{
Intention to leave among health care professionals: The importance of working conditions and social capital
}

\author{
Marcus Strömgren* \\ KTH Royal Institute of Technology, Department of Technology \& Health, Stockholm, Sweden
}

Received: April 6, 2017

DOI: $10.5430 /$ jha.v6n3p58

\author{
Accepted: May 14, 2017 \\ Online Published: June 1, 2017 \\ URL: https://doi.org/10.5430/jha.v6n3p58
}

\begin{abstract}
Hospitals in Sweden are redesigning their care processes to increase efficiency. However, related to these changes, there is a risk of increased staff intention to leave and turnover due to increased workload and work pace. The literature on work engagement and job demands and resources suggests that specific job resources can buffer negative effects; i.e., intention to leave because of job demands. Social capital is suggested to have the potential to be a resource associated with staff intention to leave. The aim of this study was to investigate the associations between social capital and intention to leave and to test if social capital moderates the relationship between job demands and intention to leave. A sample of five hospitals working under conditions of improvements of care processes were studied using a questionnaire administered to the healthcare clinicians $(n=849)$. High levels of social capital were associated with low levels of intention to leave. However, the moderating effect of social capital was not confirmed. Intention to leave among occupational groups was influenced differently by social capital, other job resources, and job demands.
\end{abstract}

Key Words: Social capital, Intention to leave, Job demands, Job resources, Organizational improvement

\section{INTRODUCTION}

Health care organizations have been struggling with demands to decrease costs and, at the same time, to develop care processes of good quality. ${ }^{[1]}$ To reach sustainability in these kinds of organizational improvements, engaged clinicians are needed. ${ }^{[2]}$ Research has shown that a highly engaged work force positively predicts employee outcomes and organizational success. ${ }^{[3,4]}$ However, research of hospitals working with organizational developments - i.e., implementing management systems in order to rationalize and redesign care processes - have shown negative consequences (increased workload and stress) for the staff. ${ }^{[5]}$ The negative effects of increased workload and stress are suggested to be a consequence of poor match between job demands and job resources. ${ }^{[6]}$ Previous research on the importance of working conditions during the redesign of care processes indicate that quantitative demands and work pace are important demands to consider. ${ }^{[7]}$ With respect to job resources, predictability role clarity, leadership quality, recognition, and development opportunities were shown to be important during the redesign of care processes. ${ }^{[7]}$ In hospital settings, engagement of clinicians - i.e., physicians, nurses, and allied health care professionals - has been stressed to be crucial for the redesign of care processes in order for these to be sustainable. ${ }^{[2]}$ On the contrary, other studies have shown that there is a difficulty in engaging health care professionals in organizational

\footnotetext{
*Correspondence: Marcus Strömgren; Email: marcus.stromgren@ regionvastmanland.se; Address: KTH Royal Institute of Technology, Department of Technology \& Health, Stockholm, Sweden.
} 
improvements of care processes. ${ }^{[8-11]}$ The literature also describes health care organizations' culture as characterized by limited trust and limited collaboration between different occupational groups and organizational levels. ${ }^{[12,13]}$ Despite these hindering factors, there is potential to overcome these obstacles.

\subsection{Intention to leave}

In parallel with the last decade's developments in Swedish public hospitals (i.e., cost savings, rationalizations, and redesign of care processes), work related illnesses have increased $^{[14]}$ and there is now a problem of high staff turnover. An international study conducted in different countries showed that approximately a third of nurses were dissatisfied with their work situation. ${ }^{[15]}$ Studies of health care employees' work environment have shown that stress and workload are associated with perceptions of job resource levels, which in turn have led to a focus on job resources in order to decrease staff turnover and to influence staff engagement. ${ }^{[16,17]}$ Intention to leave refers to the subjective estimation of leaving the organization in the near future. ${ }^{[18]}$ This makes it interesting and even important to further investigate such a relationship between resource levels and intention to leave; such knowledge could influence employees' intention to leave in a more desirable direction. In previous research, intention to leave has indicated and predicted employees' future turnover ${ }^{[19]}$ and is therefore suitable to use as a measure of conditions prior to the actual incidence of turnover.

\subsection{Job demands, job resources, and intention to leave}

Previous research stresses that job demands and job resources are important with respect to staff turnover and staff intention to leave. ${ }^{[6,20]}$ The framework of the Job Demands-Resources (JD-R) model assumes that different work has its own job resources and job demands, which in turn have consequences for the individuals as well as for the organization. ${ }^{[21]}$ According to the model, beneficial working conditions can foster both motivation and health-related sustainability among staff and therefore improve individual as well as organizational outcomes. ${ }^{[22]}$ The JD-R model suggests that resources and demands could interact with each other; for example, resources have the potential to buffer the negative consequences of the demands. In the theoretical model, job resources are associated with engagement because of the resources' potential to engage individuals in their work. ${ }^{[22]}$ In previous studies, both job demands and job resources have proven to be associated with intention to leave and the JD-R model makes it possible to investigate other potential resources in relation to employees' intention to leave. Job resources such as leadership quality and role clarity contribute to reduced quantitative demands at work. ${ }^{[7]}$ Other job

Published by Sciedu Press resources to be considered are social network at the work place, human relations, and good work relations between colleagues; these have shown to be associated with intention to leave, ${ }^{[16]}$ which indicates that social capital can be a potential resource.

\subsection{Social capital and intention to leave}

The concept of social capital is introduced here as a possible resource which may be associated with employees' intention to leave. Based on mutual trust between employees, trust between employees and the manager, reciprocity, and recognition, ${ }^{[23-27]}$ social capital has been shown to be an important factor for health care professionals' well-being, job satisfaction, general work engagement, and engagement in clinical improvements of patient safety. ${ }^{[28,29]}$ Social capital has also been suggested to be associated with staff turnover ${ }^{[30]}$ and lower emotional exhaustion and burnout. ${ }^{[31]}$ Research implies considering social capital as an important factor with respect to staff turnover. Studies of the importance of supportive social relationships ${ }^{[32]}$ and trust ${ }^{[33,34]}$ at workplaces have been found to influence employees' intent to leave. Research in hospital settings shows that low levels of staff turnover is associated with high levels of social capital. ${ }^{[35]}$ However, to our knowledge there is a deficiency in studies investigating social capital as a job resource in relation to staff intention to leave, which could be considered to be a prior condition before turnover happens.

In sum, high staff turnover seems to make it difficult for health care organizations to succeed in developing care in a sustainable way. Specific job demands interplay with specific job resources and are associated with staff engagement and intention to leave. Social capital has been shown to be a potential resource to be understood in the framework of work engagement and the JD-R model. Therefore, there is a need to focus on and to investigate the factors which could have importance for employees' decreased intention to leave. Prior knowledge indicates that social capital can be a possible resource that is associated with employees' intention to leave, and that as a resource it could interact with job demands and other job resources with respect to employees' intention to leave. Testing and investigating job demands, social capital, and other job resources with respect to intention to leave, with support from the framework of the JD-R model, will extend previous research.

\section{AIM}

The aim of this study was to assess job demands, social capital, and other job resources associated with intention to leave, and to investigate if social capital moderates the association between job demands and intention to leave. The hypotheses 
proposed were that:

Hypothesis 1: Social capital is negatively associated with intention to leave.

Hypothesis 2: Social capital moderates the relationship between job demands and intention to leave (see Figure 1).

Hypothesis 3: Levels of social capital are associated with levels of intention to leave, such as high levels of social capital being associated with low levels of intention to leave and low levels of social capital being associated with high levels of intention to leave.

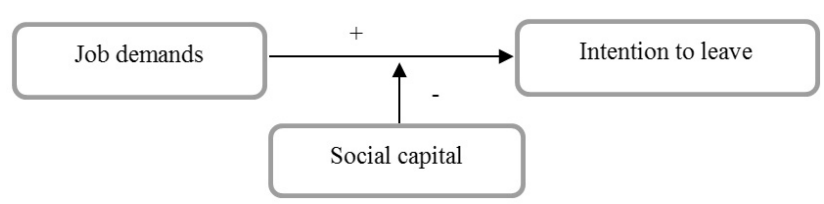

Figure 1. Hypothesized model of the interaction of social capital with job demands and intention to leave

\section{METHOD}

\subsection{Study design}

Job demands, job resources, social capital, and employees' intention to leave were investigated in a cross-sectional study. Questionnaires were distributed to health care professionals at five hospitals, all of which were working under conditions of changes to their care processes. The importance of job demands, social capital, other job resources, and employees' intention to leave — stratified to occupational groups — was assessed using bivariate and multivariate analyses.

\subsection{Sample and study population}

The study was performed in hospital settings. A sample of five hospitals, under conditions of ongoing development of care processes, was selected. The inclusion criteria were as follows: small (approx. 100 beds and 700 employees) or mid-sized hospitals (approx. 500 beds and 4,000 employees), located in an urban area and working under conditions of developing care processes. Different specialties of care units were selected to get a broader view of the questions asked in the study: emergency units, acute medical and surgical intake units (or intensive care units [ICUs] at the small hospitals), and one medical or surgical ward were included. Because of the variation in how the physicians were connected to a certain unit, the decision was made to include all physicians at the hospitals. Because of ongoing parallel engagement with research and development, one hospital consented to include staff from their surgical department. Another hospital only consented to include physicians connected to the units of interest. The staff had to have a minimum of six month's employment at the actual unit to be eligible for the survey. All the hospitals approached agreed to participate (see Figure 2$)$, and the response rate was $54 \%(\mathrm{n}=849)$. In total, 233 assistant nurses, 381 registered nurses, and 224 physicians participated. Most participants were women (74\%) and nearly half of the participants at baseline had worked in their professions for more than 14 years (see Table 1). 11 respondents could not be linked to profession and was considered as missing.

\subsection{Data collection}

A questionnaire was distributed by e-mail or via a sealed envelope to postal boxes at the hospital (with a stamped reply envelope) and two reminders (email or mail) were sent to participants who did not respond. A unique code was given to each participant to make it possible to send out a reminder. On the first page of the questionnaire, it was stated that by answering the questionnaire the respondent agreed to participate in the study. The study was ethically approved according to Swedish legislation governing ethics in research. The respondents were informed that participation was voluntary and that they could at any time choose to withdraw their participation. The questionnaire included validated instruments and questions regarding work-related resources and demands, organizational conditions, work processes, work engagement, and work-related health. The tools that were used came from the second version of the Copenhagen Psychosocial Questionnaire (COPSOQ II) ${ }^{[26]}$ and the Modern Work life Questionnaire (MWQ). ${ }^{[36]}$ Data collection occurred during April and May 2012 (for two hospitals) and October and November 2012 (for three hospitals).

\subsection{Measures}

Social capital (Cronbach's alpha 0.73) was constructed from the sum of four indexes: recognition (three items, Cronbach's alpha 0.82), trust regarding management (two items), mutual trust between employees (two items), and reciprocity (three items, Cronbach's alpha 0.89). Recognition, trust regarding management, and mutual trust between employees were measured by validated indexes from the second version of the Copenhagen Psychosocial Questionnaire (COPSOQ II), while reciprocity was measured by a validated index from the Modern Work life Questionnaire. ${ }^{[36]}$ All items were rated on a five-grade scale: to a very large extent, to a large extent, somewhat, to a small extent, to a very small extent.

The dependent variable intention to leave was assessed by a single-item: "How often have you thought about applying for another job?" The response scale had five grades: never/almost never, seldom, sometimes, often, always.

Job demands were assessed using two validated indexes: 
quantitative demands (four items, Cronbach's alpha 0.83) and work pace (three items, Cronbach's alpha 0.83). The job resources were measured using validated indexes from COPSOQ II. The indexes used were: predictability (two items, Cronbach's alpha 0.61), influence (four items, Cronbach's alpha 0.70), role clarity (three items, Cronbach's alpha 0.78), development opportunities (four items, Cronbach's al- pha 0.69), and leadership quality (eight items, Cronbach's alpha 0.93). Because of multicollinearity between social capital and recognition, recognition was excluded. All items in job demands and job resources had a five grade scale: never/almost never, seldom, sometimes, often, always.

According to normal procedures when using scales from COPSOQ, the items were recalculated to $0-100$ points.

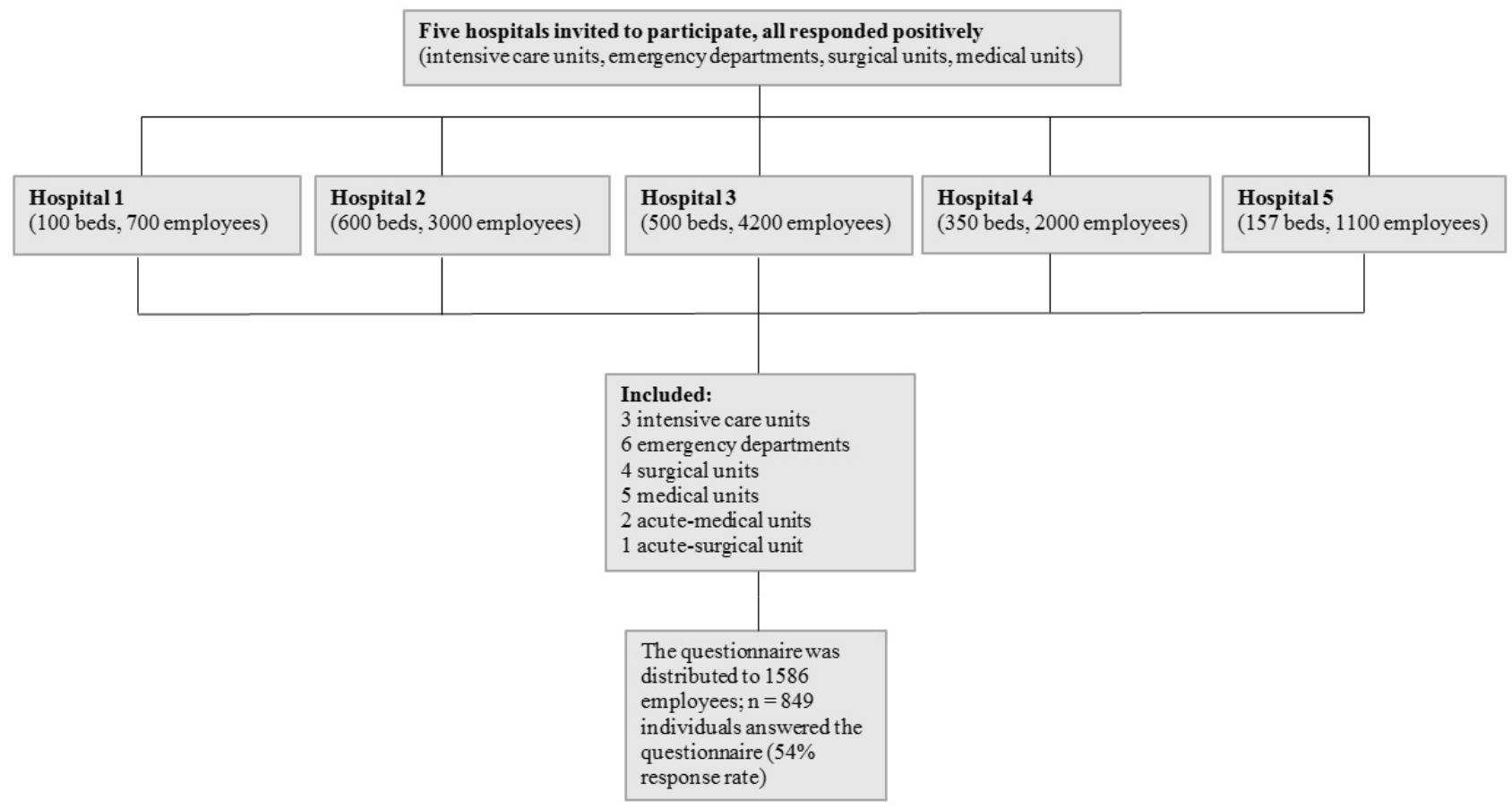

Figure 2. Schematic chart showing the study sites and subjects

Table 1. Characteristics of the study group

\begin{tabular}{|c|c|c|c|c|c|c|c|c|c|}
\hline & & \multicolumn{2}{|c|}{ All } & \multicolumn{2}{|c|}{ Assist. nurses } & \multicolumn{2}{|c|}{ Nurses } & \multicolumn{2}{|c|}{ Physicians } \\
\hline & & $\mathbf{n}$ & $\%$ & $\mathbf{n}$ & $\%$ & $\mathbf{n}$ & $\%$ & $\mathbf{n}$ & $\%$ \\
\hline All & & 838 & 100 & 233 & 28 & 381 & 45 & 224 & 27 \\
\hline \multirow[t]{2}{*}{ Sex } & - Female & 630 & 75 & 210 & 34 & 337 & 54 & 79 & 13 \\
\hline & - Male & 206 & 25 & 20 & 10 & 42 & 20 & 144 & 70 \\
\hline \multirow[t]{3}{*}{ Years in profession } & - $<2 \mathrm{yrs}$ & 29 & 6 & 5 & 17 & 21 & 72 & 3 & 10 \\
\hline & - $2-7 \mathrm{yrs}$ & 92 & 19 & 14 & 15 & 60 & 65 & 18 & 20 \\
\hline & - $>14$ yrs & 260 & 52 & 118 & 45 & 103 & 40 & 39 & 15 \\
\hline
\end{tabular}

\subsection{Analysis}

Descriptive statistics of job demands, job resources, social capital, and intention to leave - stratified into occupational groups - were conducted. A Student's $t$-test was used to perform comparisons between occupational groups (see Table 2). Pearson's correlation was performed for bivariate associations between investigated variables. A Student's $t$-test was used to compare if levels of social capital in relation to levels of intention to leave differed. Linear regression models were used to investigate if social capital moderated the relationships between job demands and intention to leave (see Table 3). For example, to examine Hypothesis 2, the simple effect of job demands was added in the first step and social capital was added in the second step. Finally, the product of job demands and social capital was added in a third step. Before creating the interaction term, the predictors (job demands and social capital) were centered by subtracting each value from its respective mean in order to achieve a bet- 
ter estimate of the interaction term. ${ }^{[37]}$ In order to investigate the contribution of social capital, job demands, and other job resources for intention to leave, linear regression models were performed, also stratified into occupational groups (see Table 3). In the literature it has been suggested that there might be a difference between older employees compared with younger employees. ${ }^{[38]}$ Age information was not available, but information about how long the respondents had worked in their present occupation was available. The variable was dichotomized into two approximately similar sized groups $(0=$ up to 14 years and $1=$ more than 14 years $)$.

The data were approximately normally distributed. In the analyses, statistical significance was considered when $p<.05$. The correlation was considered to be weak at $r \leq 0.20$, fair at $r=0.21-0.40$, moderate at $r=0.41-0.60$, strong at $r=0.61-0.80$, and very strong at $r=0.81-1.00 .^{[39]}$ All statistical calculations were performed using JMP version 10.0.2 (SAS Institute, Cary, NC, USA).

Table 2. Intention to leave regressed on job demands and social capital

\begin{tabular}{llll}
\hline \multirow{2}{*}{ Steps } & \multicolumn{3}{c}{ Intention to leave } \\
\cline { 2 - 4 } & $\boldsymbol{\Delta R}^{2}$ & $\boldsymbol{\beta} / \boldsymbol{p}$-value & $\boldsymbol{S E}(\boldsymbol{\beta})$ \\
\hline Step 1 & 0.10 & & \\
$\quad$ • Job demands & & $0.56 /<.0001$ & 0.06 \\
Step 2 & 0.09 & & \\
$\quad$ - Job demands & & $0.43 /<.0001$ & 0.06 \\
• Social capital & & $-0.63 /<.0001$ & 0.07 \\
Step 3 & 0.00 & & \\
$\bullet$ & & $0.43 /<.0001$ & 0.06 \\
• Job demands & & $-0.63 /<.0001$ & 0.07 \\
• Jocial capital & & $-0.01 / \mathrm{n} . \mathrm{s}$. & 0.01 \\
\hline Total $R^{2}$ & 0.19 & & \\
\hline
\end{tabular}

Note. n.s. = not significant

Table 3. Importance of job demands, job resources, and social capital for intention to leave among occupational groups

\begin{tabular}{llll}
\hline & \multicolumn{3}{c}{ Intention to leave $(\boldsymbol{\beta} / \boldsymbol{p}$-value) } \\
\cline { 2 - 4 } & Physicians & Nurses & Assistant nurses \\
\hline Job demands & $0.390 / .001$ & $0.401 /<.0001$ & $0.623 /<.0001$ \\
Job resources & $-0.676 /<.0001$ & $-0.331 / .02$ & $-0.352 / .07$ \\
Social capital & $-0.265 / .08$ & $-0.523 / .001$ & $-0.241 / .184$ \\
Intercept & $66.95 /<.0001$ & $69.68 /<.0001$ & $42.459 / .001$ \\
$R^{2}$ & 0.29 & 0.18 & 0.24 \\
$F$-value & 27.54 & 23.69 & 18.55 \\
\hline
\end{tabular}

\section{RESUlts}

\subsection{Job demands, job resources, social capital, and in- tention to leave}

Job demands, job resources, and social capital were associated with intention to leave. Social capital and job resources were about equally associated with intention to leave. The result showed that social capital was negatively associated with intention to leave ( $r=0.37)$, while job demands were positively associated with intention to leave $(r=0.33)$. Job resources were negatively associated with intention to leave $(r=0.36)$.

\subsection{Job demands, job resources, social capital, and in- tention to leave among health care professionals}

When stratified to occupational groups, the results showed that physicians rated job demands higher $(M=61.88$, $S D=14.87$ ) compared with the other occupational groups. The assistant nurses rated the job demands $(M=51.44$, $S D=13.97$ ) lower compared with nurses and physicians With respect to levels of social capital, the physicians scored the highest $(M=70.93, S D=13.51)$. Lowest ratings of intention to leave were seen among physicians $(M=31.81$, $S D=25.96)$ compared with nurses who rated intention to leave highest $(M=38.50, S D=24.04)$. No significant difference was shown between nurses and assistant nurses with respect to intention to leave. Levels of job resources were approximately equally distributed among the occupational groups and no significant difference was shown.

\subsection{Associated levels of social capital and levels of inten- tion to leave}

Results of the analysis of the association between levels of social capital and levels of intention to leave support Hypothesis 3. Those with high levels of social capital showed a lower degree of intention to leave $(M=25.29, S D=23.59)$ compared with those with low levels of social capital where the degree of intention to leave was higher $(M=48.77$, $S D=23.19$ ). When stratified to occupational groups, the results remained the same.

\subsection{Moderating effect of social capital}

The results of the analyses of social capital's moderating effect on the relationship between job demands and intention to leave showed no interaction (see Table 2). From these results, we could not determine whether social capital influenced the association between job demands and intention to leave in such a way that intention to leave decreases. Hypothesis 2 was not confirmed, nor was the hypothesized model (see Figure 1) of the moderating effect of social capital on the relationship between job demands and intention to leave.

\subsection{Importance of job demands, job resources, and so- cial capital for intention to leave}

The importance of job resources, job demands, and social capital for intention to leave was analyzed. Of the total sample, the model explained $21 \%$ of the variation of intention to leave. Job demands, social capital, and other job re- 
sources were significant in the model: job demands $(\beta=0.39$, $S E=0.06)$, social capital $(\beta=-0.45, S E=0.09)$ and other job resources $(\beta=-0.38, S E=0.10)$.

\subsection{Importance of job demands, job resources, and so- cial capital among occupational groups for intention to leave}

Among physicians, the model explained $29 \%$ of the variation of intention to leave and among assistant nurses the model explained $24 \%$ of the variation of intention to leave. For nurses, the model explained $18 \%$ of the variation of intention to leave (see Table 3).

The results showed that years in a profession had importance. For the group that had worked less years in their present occupation, social capital had greater importance (explained $25 \%$ of the variance of intention to leave) compared with those who had worked more than fourteen years in the same occupation (explained 19\% of the variance of intention to leave).

\section{Discussion}

Previous research has shown that job demands (quantitative demands and work pace) increase when working during organizational improvements in health care; i.e., the redesign of care processes. ${ }^{[7]}$ With knowledge of such consequences, it is especially important to consider resources when working under conditions of organizational improvement in health care organizations in order to decrease the risk of staff leaving the organization.

The potential of social capital as a resource which could balance and interplay with increased job demands, as well as influence negative outcomes such as employees' intention to leave, makes it an important job resource. The results in this study show that job demands, social capital, and other job resources are associated with and have importance with regard to employees' intention to leave. Hypothesis one social capital is negatively associated with intention to leave — is supported.

In line with previous research ${ }^{[2]}$ on the importance of staff engaging in organizational improvements, the study supported considering social capital as a resource important for maintaining sustainability, because of its association with decreased risk of staff leaving the organization. By connecting social capital with the JD-R model, it seems that social capital could have a predictive influence of staff intention to leave by considering it as a resource. In theory, ${ }^{[22]}$ job resources can interplay with job demands as they buffer the negative consequences of the demands. However, in this study the results of the analysis of such a relationship could

Published by Sciedu Press not prove an interactional effect of social capital with respect to job demands and intention to leave. Hypothesis two - social capital moderates the relationship between job demands and intention to leave - is not supported. In contrast with existing theory, social capital in this study does not interplay with investigated job demands. Perhaps future analyses of different dimensions of social capital interplaying with different specific job demands and job resources could shed light on such relationships.

In Demerouti and Bakker's JD-R model ${ }^{[21]}$ the actual staff turnover could be regarded as an organizational outcome. Intention to leave, however, is more of a condition before the actual turnover takes place, which raises the question of where it could be placed in the JD-R model. The dimensions of engagement and motivation, as well as strain and exhaustion in the JD-R model, lie in between job resources and organizational outcomes as well as in between job demands and organizational outcomes. Previous research has investigated organizational outcomes (i.e., intention to leave and staff turnover) in combination with engagement, ${ }^{[40]}$ motivation, strain, and exhaustion. ${ }^{[6,22]}$ Research has shown associations between levels of engagement and staff intention to leave, ${ }^{[20]}$ where highly engaged staff had lower intentions to leave and staff with low engagement were associated with high intention to leave. This suggests that social capital as a resource may influence staff intention to leave by its association with staff engagement. This was not investigated in this study, which leaves the question unanswered; but, from a theoretical perspective one can assume that social capital could be associated with engagement. However, this study has shown that there are direct associations of job demands, social capital, and other job resources with intention to leave.

The supported Hypothesis 3 (levels of social capital are associated with levels of intention to leave) showed the importance of high versus low levels of social capital with respect to intention to leave. Individuals with high levels of social capital also had lower levels of intention to leave, as compared with those with low levels of social capital who showed higher intention to leave. This suggests that levels of social capital can indicate different risks with regard to intention to leave. When stratified to occupational groups, the results were found to be stable, which means that despite occupation, levels of social capital are important for employees' intention to leave. These results are in line with previous $\operatorname{research}^{[6,21,22]}$ which stresses that increased resources have positive associations with organizational outcomes as well as with employees' intention to leave. ${ }^{[16,17]}$ In addition to other important job resources, the results in the present study show that social capital can be regarded as one resource which matters for health care professionals' intention to leave. 
The multivariate regression shows that job demands, job resources, and social capital are important for intention to leave. Demands had positive association with intention to leave while resources and social capital had negative association. However, when the multivariate regression model was stratified to occupational groups, the result showed that job demands, job resources, and social capital differed in importance with respect to intention to leave (see Table 3). This knowledge could be important to consider when targeting future actions relating to employees' intention to leave. Another possible consideration found in this study was that the years spent in the current profession had importance for intention to leave and social capital. The results showed that those who had worked less years in their current profession experienced greater influence of social capital on their intention to leave than those who had worked a longer time in their current profession. Years in the current profession do not reveal the actual age of the person. However, it gives an impression of how experienced the employees are and there is reason to believe that a person with fewer years in their current profession is also younger than a person with many years in their current profession. These results are in line with previous research; ${ }^{[38]}$ younger staff have a stronger association with intention to leave than older staff. A possible interpretation can be that social capital as a resource fills the need of social support that the younger staff have when entering hospital health care practice. ${ }^{[38]}$

\subsection{Limitations}

The cross-sectional design of this study obviously limits the possibilities to draw conclusions about causal relationships between the investigated variables. However, previous studies have shown that job demands and job resources predict both individual and organizational outcomes. ${ }^{[21,22]}$ This supports investigating social capital both as a possible resource predicting staffs intention to leave and as a moderator in the relationship between job demands and intention to leave, as well as between job resources and intention to leave. Another limitation is the reliance on self-reported data, because the respondents filled in a questionnaire which could lead to common source bias. ${ }^{[41]}$ In its favor, this study had a satisfactory sample size and response rate (54\%). The fulfillment of informed consent could have decreased the effects of the common method bias problem. The use of instruments with high reliability and validity gives strength and counterbalance to some of the mentioned weaknesses in this study. ${ }^{[42]}$

\subsection{Practical implications}

The results in this study address some important practical implications. First, as staff turnover and employees' intention to leave is a problem in health care organizations, knowledge of social capital as a resource which can be assumed to influence staffs intention to leave is important. Second, the consideration of social capital as a resource should not be underestimated by the hospital management when working on the redesign of care processes in order to make these developments sustainable. Third, the enhancement of social capital and other job resources, as well as decreasing job demands in the organization, may be a strategical managerial incitement to influence intention to leave among health care professionals. Lastly, attention should be paid to the importance of social capital for the younger staff as a strategy against them leaving the organization.

In the JD-R model, job resources are proposed to influence engagement. Social capital could possibly be a resource in such a relationship and, therefore, future research should focus on investigating social capital over time with respect to work engagement and other forms of engagement. This calls for longitudinal research designs.

\section{Conclusions}

- Social capital is associated with health care professionals' intention to leave.

- Social capital was not confirmed as having a moderating effect in the relationship between job demands and intention to leave.

- Levels of social capital are associated with levels of intention to leave.

- Intention to leave among occupational groups is influenced differently by social capital, job resources, and job demands.

\section{FUNDING}

This project was supported by the Swedish Research Council for Health, Working Life and Welfare (FORTE 2016-00484).

\section{ETHICAL APPROVAL}

The study was approved by the Central Ethical Review Board at Karolinska Institute, Stockholm, Sweden.

\section{ACKNOWLEDGEMENTS}

We are grateful to FORTE, the Swedish Research Council for Health, Working Life and Welfare (2016-00484), for financial support.

\section{CONFlicts OF INTEREST Disclosure}

The authors declare they have no conflict of interest. 


\section{REFERENCES}

[1] Magnussen J, Vrangbaek K, Saltman RB. Nordic Health Care Systems : Recent Reforms and Current Policy Challenges. Berkshire, GBR: McGraw-Hill Education; 2009.

[2] Riches E, Robson B. Clinical engagement: improving healthcare together. Scott Med J. 2014; 59: 62-66. PMid: 24434856. https : //doi.org/10.1177/0036933013520117

[3] Saks AM. Antecedents and consequences of employee engagement. Journal of Managerial Psychology. 2006; 21: 600-619. https: //doi.org/10.1108/02683940610690169

[4] Bakker AB, Schaufeli WB. Positive organizational behavior: Engaged employees in flourishing organizations. Journal of Organizational Behavior. 2008; 29: 147-154. https ://doi .org/10.1002/ job. 515

[5] Westgaard RH, Winkel J. Occupational musculoskeletal and mental health: Significance of rationalization and opportunities to create sustainable production systems - A systematic review. Appl Ergon. 2011; 42: 261-296. PMid: 20850109. https ://doi.org/10.101 6/j.apergo.2010.07.002

[6] Jourdain G, Chenevert D. Job demands-resources, burnout and intention to leave the nursing profession: a questionnaire survey. Int $\mathbf{J}$ Nurs Stud. 2010; 47: 709-722. PMid: 20138278.

[7] Dellve L, Williamsson A, Strömgren M, et al. Lean implementation at different levels in Swedish hospitals: the importance for working conditions and stress. International Journal of Human Factors and Ergonomics. 2015; 3: 235-253. https://doi.org/10.1504/IJ HFE. 2015.073001

[8] Braithwaite J, Westbrook MT, Travaglia JF, et al. Are health systems changing in support of patient safety? A multi-methods evaluation of education, attitudes and practice. Int J Health Care Qual Assur. 2007; 20: 585-601. PMid: 18030960. https://doi.org/10.1108/09 526860710822725

[9] Riley WJ, Moran JW, Corso LC, et al. Defining quality improvement in public health. J Public Health Manag Pract. 2010; 16: 57. PMid: 20009636. https://doi.org/10.1097/PHH.0b013e 3181 bedb49

[10] Hertting A, Nilsson K, Theorell T, et al. Downsizing and reorganization: demands, challenges and ambiguity for registered nurses. J Adv Nurs. 2004; 45: 145-154. PMid: 14705999. https ://doi .org/10 $.1046 / j .1365-2648.2003 .02876 . x$

[11] Lindgren A, Baathe F, Dellve L. Why risk professional fulfilment: a grounded theory of physician engagement in healthcare development. Int J Health Plann Manage. 2013; 28: e138-157. PMid: 23169393. https://doi.org/10.1002/hpm. 2142

[12] Glouberman S, Mintzberg H. Managing the care of health and the cure of disease-Part I: Differentiation. Health Care Manage Rev. 2001; 26: 56-69; discussion 87-59.

[13] Mitchell R, Parker V, Giles M, et al. Review: Toward realizing the potential of diversity in composition of interprofessional health care teams: an examination of the cognitive and psychosocial dynamics of interprofessional collaboration. Med Care Res Rev. 2010; 67: 326. PMid: 19605620. https://doi.org/10.1177/1077558709 338478

[14] Hasselhorn HM, Müller BH, Tackenberg P. NEXT scientific report July 2005. Wuppertal: University of Wuppertal. 2005.

[15] Aiken LH, Cimiotti JP, Sloane DM, et al. Effects of nurse staffing and nurse education on patient deaths in hospitals with different nurse work environments. Med Care. 2011; 49: 1047-1053. PMid: 21945978. https://doi.org/10.1097/MLR.0b013e3182330b $6 e$

[16] Carter MR, Tourangeau AE. Staying in nursing: what factors determine whether nurses intend to remain employed? J Adv Nurs. 2012;
68: 1589-1600. PMid: 22458811.https://doi.org/10.1111/j. 1365-2648.2012.05973.x

[17] Collini SA, Guidroz AM, Perez LM. Turnover in health care: the mediating effects of employee engagement. J Nurs Manag. 2015; 23 : 169-178. PMid: 24118346. https://doi.org/10.1111/jonm.1 2109

[18] Mowday RT, Porter LW, Steers RM. Employeeorganization linkages: The psychology of commitment, absenteeism and turnover. New York: Academic Press. 1982; 20: 167.

[19] Cho S, Johanson MM, Guchait P. Employees intent to leave: A comparison of determinants of intent to leave versus intent to stay. International Journal of Hospitality Management. 2009; 28: 374-381. https://doi.org/10.1016/j.ijhm.2008.10.007

[20] De Lange AH, De Witte H, Notelaers G. Should I stay or should I go? Examining longitudinal relations among job resources and work engagement for stayers versus movers. Work \& Stress. 2008; 22 201-223. https://doi.org/10.1080/02678370802390132

[21] Demerouti E, Bakker AB, Nachreiner F, et al. The job demandsresources model of burnout. J Appl Psychol. 2001; 86: 499-512. PMid: 11419809. https://doi.org/10.1037/0021-9010.86 .3 .499

[22] Bakker AB, Demerouti E. The job demands-resources model: State of the art. Journal of Managerial Psychology. 2007; 22: 309-328. https://doi.org/10.1108/02683940710733115

[23] Bourdieu P. The Forms of Capital. In: Richardson JG, editor. Handbook of Theory and Research for the Sociology of Education: Greenwood Publishing Group, Incorporated; 1986. 81-93 p.

[24] Tansley C, Newell S. Project social capital, leadership and trust: A study of human resource information systems development. Journal of Managerial Psychology. 2007; 22: 350-368. https ://doi .org/ 10.1108/02683940710745932

[25] Harpham T, Grant E, Thomas E. Measuring social capital within health surveys: key issues. Health Policy Plan. 2002; 17: 106111. PMid: 11861592. https://doi.org/10.1093/heapol/17. 1.106

[26] Pejtersen JH, Kristensen TS, Borg V, et al. The second version of the Copenhagen Psychosocial Questionnaire. Scand J Public Health 2010; 38: 8-24. PMid: 21172767. https://doi.org/10.1177/ 1403494809349858

[27] Kouvonen A, Kivimaki M, Vahtera J, et al. Psychometric evaluation of a short measure of social capital at work. BMC Public Health. 2006; 6: 251. PMid: 17038200. https://doi.org/10.1186/14 71-2458-6-251

[28] Oksanen T, Kouvonen A, Kivimaki M, et al. Social capital at work as a predictor of employee health: multilevel evidence from work units in Finland. Soc Sci Med. 2008; 66: 637-649. PMid: 18006128. https://doi.org/10.1016/j.socscimed.2007.10.013

[29] Strömgren M, Eriksson A, Bergman D, et al. Social capital among healthcare professionals: A prospective study of its importance for job satisfaction, work engagement and engagement in clinical improvements. Int J Nurs Stud. 2016; 53: 116-125. PMid: 26315780 https://doi.org/10.1016/j.ijnurstu.2015.07.012

[30] Krachardt D, Hanson J. Informal networks: the company behind the charts. Harvard Business Review. 1993; 71: 104-111.

[31] Kowalski C, Ommen O, Driller E, et al. Burnout in nurses - the relationship between social capital in hospitals and emotional exhaustion. J Clin Nurs. 2010; 19: 1654-1663. PMid: 20384668. https://doi.org/10.1111/j.1365-2702.2009.02989.x

[32] Ellett AJ, Ellis JI, Westbrook TM. A qualitative study of 369 child welfare professionals' perspectives about factors contributing to employee retention and turnover. Children and youth services review. 
2007; 29: 264-281. https://doi.org/10.1016/j.childyouth .2006 .07 .005

[33] Costigan RD, Iiter SS, Berman JJ. A multi-dimensional study of trust in organizations. Journal of managerial issues. 1998; 303-317.

[34] Bobbio A, Manganelli AM. Antecedents of hospital nurses' intention to leave the organization: A cross sectional survey. Int J Nurs Stud. 2015; 52: 1180-1192. PMid: 25863657. https: //doi.org/10.1016/j.ijnurstu.2015.03.009

[35] Stordeur S, D'Hoore W, Group NES. Organizational configuration of hospitals succeeding in attracting and retaining nurses. J Adv Nurs. 2007; 57: 45-58. PMid: 17184373. https://doi.org/10.1111/ j.1365-2648.2006.04095.x

[36] Oxenstierna G, Widmark M, Finnholm K, et al. A new questionnaire and model for research into the impact of work and the work environment on employee health. Scandinavian Journal of Work, Environment \& Health. 2008; 34: 150.

[37] Aiken LS, West SG, Reno RR. Multiple regression: Testing and interpreting interactions. Sage; 1991.
[38] Flinkman M, Salanterä S. Early career experiences and perceptions-a qualitative exploration of the turnover of young registered nurses and intention to leave the nursing profession in Finland. J Nurs Manag. 2015; 23: 1050-1057. PMid: 25186284. https: //doi.org/10.1111/jonm.12251

[39] Altman DG. Practical statistic for medical research. London: Chapman \& Hall; 1999.

[40] Halbesleben JR, Wheeler AR. The relative roles of engagement and embeddedness in predicting job performance and intention to leave. Work \& Stress. 2008; 22: 242-256. https ://doi .org/10.1080/ 02678370802383962

[41] Podsakoff PM, MacKenzie SB, Lee JY, et al. Common method biases in behavioral research: a critical review of the literature and recommended remedies. J Appl Psychol. 2003; 88: 879-903. PMid: 14516251. https://doi.org/10.1037/0021-9010.88.5.879

[42] Spector PE. Method variance as an artifact in self-reported affect and perceptions at work: Myth or significant problem? J Appl Psychol 1987; 72: 438. https://doi.org/10.1037/0021-9010.72.3 .438 